\title{
Will the Poor in Nigeria Escape Poverty in Their Lifetime?
}

\section{Zuhumnan Dapel}

\begin{abstract}
Drawing on six sweeps of household surveys of Nigeria that together span 1980-2010 with a pooled sample size of about 97,000 households and data on Nigeria's age-gender-specific life expectancy from the World Health Organization, this paper shows that about 72 percent to 91 percent of Nigeria's poor are at risk of spending their entire life below the poverty line. To show this, I estimate the duration of poverty spells and link this to the average age of the poor and to the life expectancy. I find that the poor are expected to escape poverty at the age of 85.46 years on average. However, there is heterogeneity in the exit time, with the transient poor averaging 3-7 years below the poverty line and the chronically poor averaging 37 years or more. Given these exit times and life expectancy, the mean age of the poor at their expected time of escaping poverty exceeds the average life expectancy, meaning some of the poor are not guaranteed to escape poverty in their remaining lifetime. The implication is that growth in Nigeria has not been sufficient nor has it demonstrated the potential to help the poor break free from poverty. However, like Brazil, Nigeria can significantly reduce poverty without absolute reliance on economic growth by reducing its high inflation rate and substantially expanding its social security and social assistance transfers.
\end{abstract}

Keywords: Nigeria, Poverty, Growth, Life expectancy, duration of poverty spell

JEL: F6

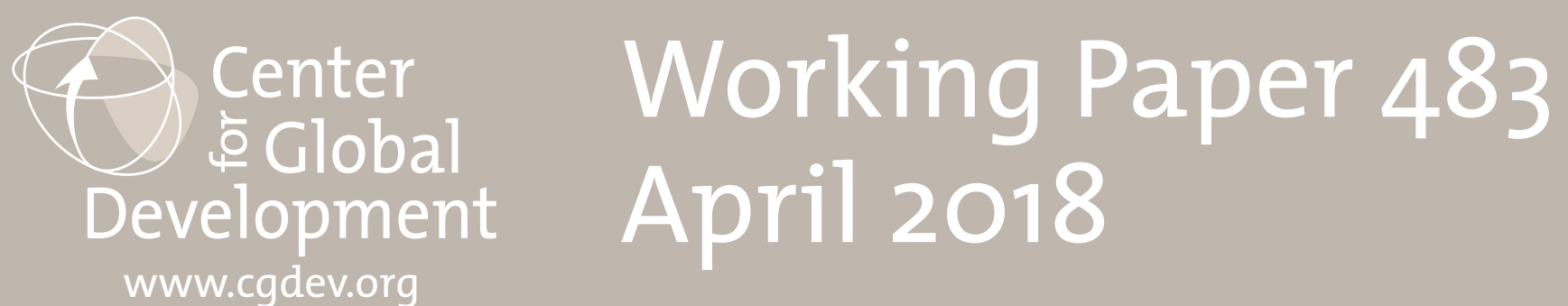




\title{
Will the Poor in Nigeria Escape Poverty in Their Lifetime?
}

\author{
Zuhumnan Dapel \\ Center for Global Development
}

The author is grateful for the support received from Jonathan Morduch, Professor of Public Policy and Economics, NYU Wagner Graduate School of Public Service; Sebastian Bauhoff, Center for Global Development; Justin Sandefur, Center for Global Development; Professor David Ulph, Scottish Institute for Research in Economics, University of St Andrews; and Emily Schabacker, Center for Global Development.

The Center for Global Development is grateful for contributions from the International Development Research Centre and the Scottish Institute for Research in Economics in support of this work.

Zuhumnan Dapel, 2018. "Will the Poor in Nigeria Escape Poverty in Their Lifetime?" CGD Working Paper 483. Washington, DC: Center for Global Development. https://www.cgdev.org/publication/will-poor-nigeria-escape-poverty-their-lifetime

Center for Global Development 2055 L Street NW Washington, DC 20036

202.416 .4000

(f) 202.416 .4050

www.cgdev.org
The Center for Global Development is an independent, nonprofit policy research organization dedicated to reducing global poverty and inequality and to making globalization work for the poor. Use and dissemination of this Working Paper is encouraged; however, reproduced copies may not be used for commercial purposes. Further usage is permitted under the terms of the Creative Commons License.

The views expressed in CGD Working Papers are those of the authors and should not be attributed to the board of directors, funders of the Center for Global Development, or the authors' respective organizations. 


\section{Contents}

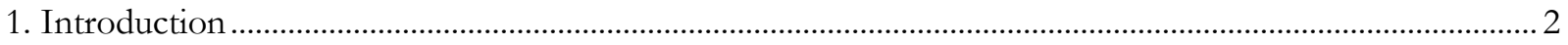

2. Model and approach ................................................................................................................................. 3

2.1. Measuring the duration of poverty spell and growth in income of the poor .......................................... 4

2.2. Estimating exit time from cross-section survey ..................................................................................... 5

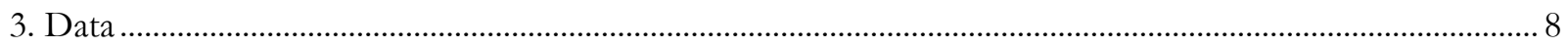

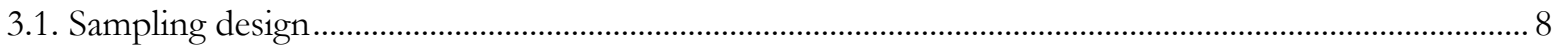

3.2. Definition of poverty lines in Nigeria ....................................................................................................... 9

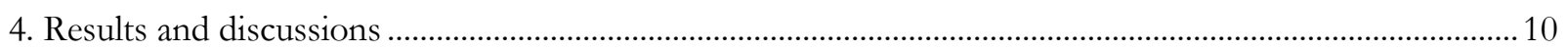

5. Policy conclusions ......................................................................................................................... 13

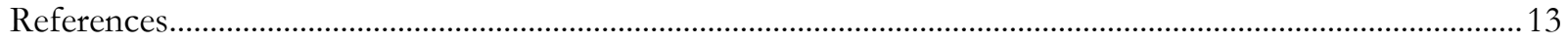


"We believe that the duration aspect of time merits particular attention for four main reasons. First, there is a simple logic that says if $x$ has experienced the same forms and depths of poverty as $y$, but for a much longer period, then a moral concern with helping the worst off requires that $x$ be prioritised and supported as $s /$ he has experienced more deprivation than $y$. In this example $x$ is not poorer than $y$ as the form and depth of the deprivation in question are equivalent. $X$, however, has been poorer for longer than $y$ (possibly for much longer than y), and arguably this ought to count for sometbing morally speaking. In this case we might accept that $x$ is generally worse than $y$, although not necessarily poorer than $y$. In this example the lives of both $x$ and $y$ are blighted by their deprivation. If we formally classify $x$ as poorer than $y$, we risk obscuring the deprivation of $y$, which may well be quite serious." -Clark and Hulme (2005).

\section{Introduction}

As the quotation above makes clear, one way of looking at the extent of poverty or level of deprivation of the poor is to study the duration of poverty spells, defined as time spent below a threshold of average living standards before escaping poverty. Relating the duration of poverty spells to life expectancy provides a picture of the extent of poverty and whether the poor can potentially escape from it in their lifetime.

In a famous study measuring time spent in poverty, Morduch (1998) uses household cross-section surveys of Bangladesh to show the impact of a hypothetical GDP per capita growth rate on poverty reduction. Linking the hypothetical growth rate with household consumption, he proposes an approach for estimating average exit time from poverty. The framework provides connections between the initial incomes of poor households, estimated growth rates, and the time they can expect to be below poverty lines (under the assumptions). It is an "if-then" exercise rather than a predictive one, but it helps to shape conversations around the possibilities of economic growth for the poor.

Morduch bases his methodology on two assumptions. First, he assumes that the growth rate is constant over time. The assumption of a constant growth rate for everyone allows the "what if' question: how quickly would the time in poverty fall if everyone's income (or consumption) grew at the same rate? Second, he assumes that the gains from the growth are uniformly distributed across the entire population-that is, the slope of the Lorenz curve is zero or growth is distribution-neutral at least.

But arguably, Morduch's assumptions are less likely to hold for a number of reasons. First, the presence of heterogeneity in household consumption across time and space (Jalan and Ravallion, 2002) introduces noise in the measure of growth and therefore invalidates the assumption that growth is uniform for households over time. Second, inequality changes (rises or falls) with growth (Kuznets, 1955; and Lundberg and Squire 2003) and thus, the gains from growth are not equally distributed across households as assumed by Morduch.

To account for these shortcomings, this study uses a panel dataset to measure growth in household per capita consumption expenditure (see the methodology section for details). Panel data track the consumption of the same households over time and therefore uses the "growth rate in survey mean of consumption of households" instead of Morduch's "hypothetical growth rate." This modification addresses the concern about the assumption of inequality in measuring the average exit time from poverty. Before returning to this, it is important to look at some similar previous studies in this regard.

Bane and Ellwood (1986) and Duncan et al. (1984) also introduce spell durations and exit probabilities in their analysis of poverty dynamics. They define the poverty spell as beginning the first year an individual's income falls below the poverty line; it ends when the income rises above the line. The exit probabilities are defined as the chances of an individual escaping poverty (i.e., ending a poverty spell) conditional on the 
duration spent below the poverty line. Although they use income as the welfare indicator variable, they note that such a variable is highly volatile, e.g., due to measurement error usually associated with most surveys in developing countries (Deaton, 1997). This may result in a false "spell," causing a false beginning or end, given that a slight "random" change in income may move people in and out of poverty within a short span of time even though no significant changes in their incomes have taken place. To address this potential bias in identifying a spell, Bane and Ellwood excluded from their analysis households that experience only one-year spell.

Stevens (1994), however, notes that eliminating one-year spells ignores the tendency for people to experience repeated episodes of poverty, or multiple spells. She notes that "one way to assess the importance of repeated spells of poverty is to examine the duration of subsequent nonpoverty spells," that is, the likelihood of returning to poverty after escaping it, regardless of the duration of the spell. Corroborating this, Andriopoulou and Tsakloglou (2011) use the European Community Household Panel to show that "the probability of exiting poverty falls with previous experiences in poverty." At the same time, there is a high probability of those previously poor falling back into poverty as a decreasing function of years spent above the poverty line. In this setting, the longer-term poor have a low probability of exit and high probability of reentry, which tend to reinforce each other so that the lower the probability of exit, the higher the probability of re-entry. Furthermore, households experiencing shorter spells in poverty tend to have different characteristics than the longer-term poor. In the same vein, Stevens's results, obtained using the US Panel Study of Income Dynamics, revealed that "after one year out of poverty, 27 percent of those previously poor have started a new poverty spell. Of those that survive non-poor for a second year, 16 percent will fall back into poverty during the next year."

Applying this method to construct poverty spell and calculate exit probabilities over consecutive years requires longitudinal household surveys spanning several years. (Andriopoulou and Tsakloglou,

2011). However, Nigeria lacks this data: its available household surveys are not only sporadic but also repeated independent cross-sections (FOS, 1999 and NBS, 2012). Attempting to meet the data requirement by following Deaton (1985) to construct a pseudo panel or Dang et al. (2014) to construct a synthetic panel does not resolve this problem: the irregularly spaced nature of the dataset remains a major limitation in calculating yearly exit probabilities, let alone estimating the associated hazard model using a logit specification. It is therefore beyond the scope of this paper to analyze the duration spell aspect of poverty dynamics on an annual basis.

The layout of this paper is as follows. Section 2 presents the approach and methodology. The dataset explored for the study is described in section 3. Section 4 contains a discussion of the findings and section 5 presents policy conclusion.

\section{Model and approach}

I explore the latest large-scale (with a sample of 34,799 individual households) available household survey of Nigerian households (from 2010) to analyze the links between the age-and-gender-specific life expectancy $L_{k t}$ 1(i.e., life expectancy at age group $k$ in year $t$, where every individual $i \in k$ ), exit time from poverty $\mathrm{T}_{i}$, and the age of household head $A_{i}$ to answer the question posed in this paper's title: can Nigeria's poor escape

11. $L_{k t}$ differs from life expectancy at birth in that it varies by time and gender, making it suitable for the estimation of dynamic parameters. 
poverty in their lifetime? Given the growth rate in income (or consumption), age, the duration of poverty spell, and the life expectancy at birth of the poor, we set out to assess the fraction of the poor that is likely to escape poverty at any age below the life expectancy.

If $A_{i}$ is taken as age of household head $i$ with income (or consumption) below the poverty line, at the time of compiling the latest and largest available dataset, that is, 2010, and $T_{i}$ is the calculated duration of poverty spells of the household head conditional on growth (details on how this is obtain are explained below), then the household head is expected to escape poverty at the age of $A_{i}^{e}\left[=A_{i}+T_{i}\right]$ years old, given that $\ni \forall A_{i} \leq$ $L_{k t}$. It follows, therefore, if $A_{i}^{e}<L_{k t}$, the head will escape poverty before ageing to the life expectancy; in other words, there is a chance that a household head will grow out of poverty before reaching his/her life expectancy. Therefore, if $A_{i}^{e}<L_{k t}$, the household head will escape poverty and after this, live $\gamma_{i}\left[=L_{k t}-A_{i}^{e}\right]$ more years before ageing to $L_{k t}$, the life expectancy, which means $\gamma_{i}>0$. But if $\gamma_{i}<0$, implying $A_{i}^{e}>L_{k t}$, the household head will not escape poverty before reaching the life expectancy. On the other hand, if $A_{i}^{e}=L_{k t}$, a case of $\gamma_{i}=0$, poverty will be escaped at the time of reaching the life expectancy.

Before proceeding to show the estimations of the duration of poverty spell and of growth in income of the poor, I now consider some important caveats:

My focus in this study is on individuals $(1,2, \ldots, q)$ with income (or consumption) $y$ below the poverty $Z$, so that $q=F(Z)(>0)$ is the proportion of the population $N$ below the poverty line $Z$, or the headcount index of poverty. Intuitively, $q$ is made up of two sets of elements (or poor individuals): (a) $A_{i}^{e}<L_{k t}$ (or $\gamma_{i}>0$ ), i.e., those who are likely to escape poverty. The parameter $\sigma$ represents this proportion; and (b) $A_{i}^{e}>L_{k t}$ (or $\left.\gamma_{i}<0\right)$, i.e., those at risk of not escaping poverty in their lifetime represented by $\theta$, therefore by default, $\theta$ and $\sigma \subseteq q$.

Following the reasoning above, if $\bar{\gamma}\left[=\sum_{i=1}^{q} \gamma_{i}\right]<0$, then $\sigma>0$ holds, implying that not everyone in $q$ will escape poverty in the future, so that $\sigma=(q-\theta)$ represents the fraction of those who will likely spend their lifetime in poverty. Otherwise, all the poor in the dataset will escape poverty at different points in time should their future incomes mimic behavioral patterns of initial income. This is likely the case and feasible in the absence of significant shocks to average living standards of the poor.

\subsection{Measuring the duration of poverty spell and growth in income of the poor}

Using cross-section data from Bangladesh, Morduch (1998) showed the impact of hypothetical GDP per capita growth rate $\mathrm{g}$ on poverty reduction. Linking the hypothetical growth rate with household consumption, he proposed a procedure for estimating average exit time from poverty. His methodology was based on two assumptions: (i) $\mathrm{g}$ is constant over time, and (ii) gains from the growth are uniformly distributed across the entire population of households, i.e., the slope of the Lorenz curve is zero.

Arguably these assumptions are rarely plausible and unlikely to hold as most economies, particularly in the developing world, are characterized by volatile growth rates and high levels of inequality in income distribution. To counter these shortcomings, I use a panel dataset. Given that panel data track the consumption of the same households over time, this section proposes the use of "growth rate in survey mean of consumption of households" instead of the "hypothetical growth rate" suggested by Morduch. This 
modification addresses the concern over the assumption of inequality in measuring the average exit time from poverty.

The original idea of a constant $g$ for everyone was to ask the "what if" question: how quickly would the time in poverty fall if everyone's income or consumption grew at rate $g$ ? I answer this question in two ways: (i) using Morduch's approach, i.e., calculating exit time using cross-section and GDP per capita; and (ii) using a revised version of his approach, i.e., exit time from a synthetic panel. This enables comparison of exit times by poverty typology (or poverty statuses, for example, transient and chronic poor). In addition, based on Ravallion and Chen (2003), I measure the growth in income of the poor and then use it, rather than GDP per capita and GDP as suggested by Morduch, as a denominator in measuring the duration of poverty spells. I rely on the period of positive growth in my data, i.e., between 1996 and 2004. Finally, I investigate the interrelationships between age-gender-specific life expectancy, age of head of household, and the duration of poverty spell to address the question, "conditional on growth, can Nigeria's poor escape poverty before ageing to life expectancy?”

\subsection{Estimating exit time from cross-section survey}

According to Morduch (1998), for a given growth rate $g$, the exit time of a poor household head, conditional on a growth rate $\mathrm{g}$, can be estimated using

$$
t_{\mathrm{g}}^{i} \approx \frac{\ln (z)-\ln \left(y_{i}\right)}{\mathrm{g}}
$$

where $i$ denotes the household, $\ln (z)$ is the natural $\log$ of poverty line level of consumption, $\ln \left(y_{i}\right)$ is the $\log$ of per capita consumption of poor household members, and $g$ is the hypothetical growth rate assumed to be positive.

In this section, I modify the above using the actual growth rate denoted by $\mathbf{g}_{i t}$, namely,

$$
t_{\mathrm{g} t}^{i} \approx \frac{\ln (z)-\ln \left(y_{i t}\right)}{\mathrm{g}_{\mathrm{it}}}
$$

\subsubsection{Measuring exit time from synthetic panel data}

As stated above, $\mathrm{g}_{i t}$ is defined as the growth of individual $i$ at time $t$.

$$
\mathrm{g}_{i t} \approx \frac{y_{i t}-y_{i t-1}}{y_{i t-1}}
$$


Since (4.43) becomes irrelevant if $\mathrm{g} \leq 0,(4.45)$ is now censored at $\mathrm{g}_{i t}>0$, i.e., the trapped poor who recorded positive growth in their consumptions between the periods in question: ${ }^{2}$

$$
t_{i t}^{t p} \approx \frac{\ln \left(z_{t}\right)-\ln \left(y_{i t}\right)}{\mathrm{g}_{i t}^{t p}}
$$

Therefore, the average exit time (of the trapped poor with $g_{i t}>0$ ) is

$$
T_{t}^{t p}=\frac{1}{N} \sum_{i=1}^{N} t_{i t}^{t p}=\frac{1}{N} \sum_{i=1}^{q} \frac{\ln (z)-\ln \left(y_{i t}\right)}{\mathrm{g}_{i t}^{t p}}
$$

\subsubsection{Accounting for inequality in measuring exit time}

The presence of inequality among the poor, which is measured by the Theil index, $L p$, increases the average exit time. The index is given by

$$
L_{p}=\frac{1}{q} \sum_{i=1}^{q}\left[\ln \left(\mu_{p}\right)-\ln \left(y_{i t}\right)\right]
$$

The additional exit time due to $L p$ is

$$
\operatorname{Lg}=\frac{\operatorname{Lp}}{g_{\text {it }}}
$$

resulting in total average exit time:

$$
\mathrm{T}_{L g}=\mathrm{T}_{\mathrm{it}}^{\mathrm{tp}}+\mathrm{Lg}
$$

If there is no inequality among the poor, the exit time remains as given in (4.43) or (4.47).

\subsubsection{Measuring growth in income (or consumption) of the poor}

Here, we replace our denominator in (4.51) with the growth rate in income (or consumption) of the poor $\mathrm{g}_{t}^{p}(p)$ as it accounts for the presence of inequality in computing exit time. We measure the growth in income of the poor as follows.

In the spirit of Ravallion and Chen (2003), let $\mathrm{F}_{\mathrm{t}}(y)$ denote the cumulative distribution function (CDF) of expenditure, the proportion of the population with income (or consumption per capita expenditure) less than $y$ at date $t$. Inverting the CDF at the $p$ th quantile gives the income of that quantile:

$$
y_{t}(p)=F_{t}^{-1}(p)=L_{t}^{\prime}(p) \mu_{t}\left(y_{t}^{\prime}(p)>0\right)
$$

\footnotetext{
2 They were not able to escape poverty despite positive growth in their real consumption.
} 
where $\mu_{\mathrm{t}}$ is the growth rate in overall mean (also referred to as ordinary mean) between two corresponding dates, $\mathrm{t}$ and $\mathrm{t}-1$; where $L_{t}(p)$ is the Lorenz curve (with slope $L_{t}^{\prime}(p)$ ), we have

$$
\mathrm{g}_{\mathrm{t}}(p)=\frac{L_{t}^{\prime}(p)}{L_{t-1}^{\prime}(p)}\left(\gamma_{t}+1\right)-1
$$

If $g_{t}(p)>0$ for all $p$, then there is first-order dominance (FOD) of the $t$ distribution at date $t_{\text {over }} \mathrm{t}_{-1}$. When (4.52) is standardised by the headcount index $\mathrm{H}_{t}$, mean growth rate of the poor is obtained:

$$
\mathrm{g}_{t}^{p}(\mathrm{p}) \equiv \frac{1}{\mathrm{H}_{\mathrm{t}}} \int_{0}^{\mathrm{H}_{\mathrm{t}}} \mathrm{g}_{\mathrm{t}}(\mathrm{p})
$$

where,

$$
\left.\log y_{t}^{*} \equiv \int_{0}^{H_{t}} \log y_{t}(p)\right] d p+\left(1-\mathrm{H}_{t}\right) \log z
$$

is the mean of $\log$ censored consumption, where the censored consumption is $\min \left[y_{t}(p), z\right]$, i.e., actual income or consumption when this is below the poverty line or otherwise the poverty line itself. Inverting the $\mathrm{CDF}$ at the $p$ th quantile gives the income of that quantile:

$$
y_{t}(p)=F_{t}^{-1}(p)=L_{t}^{\prime}(p) \mu_{t}\left(y_{t}^{\prime}(p)>0\right)
$$

(where is the growth rate in overall mean $\mu_{t}$ between two corresponding dates, $t$ and $t-1$; where $\mathrm{L}_{t}(p)$ is the Lorenz curve (with slope $\mathrm{L}_{t}^{\prime}(p)$ ), we have,

$$
\mathrm{g}_{t}(p)=\frac{\mathrm{L}_{t}^{\prime}(p)}{\mathrm{L}_{t-1}^{\prime}(p)}\left(\gamma_{t}+1\right)-1
$$

If the growth incidence curve (GIC) lies above zero everywhere, i.e., $\mathrm{g}_{t}(p)>0$ for all $p$, then there is firstorder dominance (FOD) of the $t$ distribution at date $t$ over $t_{-1}$. But if it switches sign, then one cannot in general infer whether higher-order dominance holds by looking at the GIC alone. An exception to this is when the overall mean rises and the GIC is decreasing in $p$; then there is clearly second-order dominance. ${ }^{3}$

Consequently, when (4.57) is standardized by the headcount index $H_{t}$, mean growth rate of the poor is obtained:

$$
\mathrm{g}_{t}^{p}(p) \equiv \frac{1}{H_{t}} \int_{0}^{H_{t}} \mathrm{~g}_{t}(p)
$$

\footnotetext{
${ }^{3}$ The growth rate in overall mean is also referred to as ordinary mean
} 
I complement the GDP per capita measure of the time in poverty with the growth-income-of-the-poor measure $\mathrm{g}_{t}^{p}(p)$.

\section{Data}

The main data sets (that is, the household surveys used in this study) were collected under the National Integrated Survey of Households (NISH), while the data on age-gender-specific life expectancy comes from the World Health Organization (WHO) Life Table. ${ }^{4}$ The surveys are the National Consumer Surveys (NCS), fielded in 1980, 1985, 1992; the 2003/2004 Nigeria Living Standard Survey (NLSS); and the most recent, the 2009/2010 Harmonized Nigeria Living Standard Survey (HNLSS). These surveys were conducted by the National Bureau of Statistics, Nigeria (NBS), formerly the Federal Office of Statistics, in collaboration with the World Bank, UK Department for International Development (DFID), United Nations Children's Fund (UNICEF), and the European Union. Information about the sample years and sizes of the six surveys are shown in Table 1.

Table 1. Number of surveyed households and population in Nigeria, 1980-2010

\begin{tabular}{|lll|l|}
\hline Year of Survey & Sample Size (No. of households) & $\begin{array}{l}\text { Households } \\
\text { (Million) }\end{array}$ & $\begin{array}{l}\text { Population size } \\
\text { (Million) }\end{array}$ \\
\hline 1980 & 10,280 & 17.30 & 73.69 \\
\hline 1985 & 9,317 & 18.80 & 74.7 \\
\hline 1992 & 9,697 & 20.70 & 99.2 \\
\hline 1996 & 14,395 & 24.50 & 120 \\
\hline 2004 & 19,158 & 26.60 & 126 \\
\hline 2010 & 34,799 & 38.30 & 159.7 \\
\hline
\end{tabular}

Sources: Household surveys of Nigeria 1980-2010 from the NBS and population data from the World Bank

\subsection{Sampling design}

All surveys were national in coverage, i.e., they included all the states (covering rural and urban areas) of the country under a two-stage design. The first stage was made up of clusters of housing units (HUs) called enumeration areas (EAs). The EAs were drawn from each state (stratum) of the federation. The second stage involved the selection of HUs (see FOS (1999) and NBS (2012b); Anyanwu (2005); Appleton et al. (2008); Canagarajah and Thomas (2001) for details).

The samples were weighted. Two types of weights were used in constructing estimates: one for households and one for individuals. The household weight, $\omega_{-} h, h=1, \ldots, H$ is equal to the number of households

${ }^{4}$ http://apps.who.int/gho/data/?theme $=$ main\&vid $=61200$ 
represented by a particular respondent household. The sum of all the weights equal the total number of households (not individuals) in the country.

The second is the individual weight. Since households are made up of individual(s), the weight for an individual, $\psi_{j}, j=1, \ldots, N$, in each household is obtained by multiplying the weight attached to the household $\left(\omega_{h}, h=1, \ldots, H\right)$ to which the individual belongs by the total number of individuals in the household (household size). The sum of these (across all the observations) equals the country's total population. The weights are then used in constructing estimates of population parameters for households and for the individuals.

\subsection{Definition of poverty lines in Nigeria}

Because Nigeria has no official poverty line, attempts to measure poverty in the country use different lines. As a measure of absolute poverty, Sudharshan, Ngwafon and Saji (2002); FOS (1999); and Anyanwu (2005, 2010) used two-thirds of mean consumption per capita expenditures in the 1985 survey, i.e., 395.4 per person per annum in 1985 prices. This is equivalent to $\$ 5,795.36$ per person per month in July 2016 prices. This line was later adjusted, using the consumer price index (CPI), for estimating poverty in later the years, as is the case with the 1980-96 poverty profile released by Nigeria's Federal Office of Statistics, one of the predecessors to the NBS.

In its 2004 and 2010 poverty reports, the NBS derived and adopted higher lines for measuring absolute poverty in the country. In 2004 , it used a per year line of $\$ 30,128$, equivalent to $\$ 7,804.72$ per person per month in July 2016 prices, and in 2010, an annual line of $\$ 54,401.16$ per year (or $\$ 7,406.70$ in July 2016 prices). In real terms, the 2004 line was higher than that of 2010. In deriving the 2010 absolute poverty line, the NBS used 3000 calories as the expected minimum calorific intake for the average Nigerian. This is a recommendation by a nutrition consultant as the reasonable benchmark for Nigeria, given its average food basket. For 2004, NBS calculated a minimum annual expenditure required per equivalent adult as $\$ 21,743$ on food to attain 2900 calories per person per day. This expenditure on food constitutes the threshold for extreme poverty.

However, in this study, I used the US $\$ 1.25$ in 2005 PPP. First, I used the 2005 PPP Nigerian exchange rate value of 78.58 from the World Bank. Note, absolute poverty lines reflect the standards of absolute poverty in the world's poorest countries corresponding to the same real level of well-being in all countries. I take those same lines (expressed in local currency units at 2005 prices), and inflate them to July 2016 using Nigeria's CPI.

As defined by the World Bank, this line is the mean of Cost of Basic Needs (CBN) of poverty lines across the 15 poorest countries of the world (see Chen and Ravallion (2008) and Sangraula et al. (2009) for details). In other words, it measures how poor people are by the standards used to define poverty in the poorest countries of the world. Before using this line, we revalued the consumption distributions for all the years to correspond with this line. ${ }^{5}$ The international poverty line is converted to local currencies in the corresponding

\footnotetext{
${ }^{5}$ We do not use adult equivalence (AE) scales for 1980-96 surveys because of the lack of information (e.g., age and number of children in each household) required for computing the AE.
} 
international comparison program (ICP) benchmark and is then converted to the prices prevailing at the time of the relevant household survey using the available CPI for Nigeria.

The CBN — the cost of a bundle of goods deemed sufficient for "basic needs" — is the most commonly used approach for calculating poverty lines. It first estimates the cost of acquiring enough food for adequate nutrition — usually 2,100 calories per person per day — and then adds the cost of other essentials, such as clothing and shelter. But when price information is unavailable, the food energy intake method can be used. This method plots expenditure per capita against food consumption (in calories per person per day) to determine the expenditure (or income) level at which a household acquires enough food (Haughton and Khandker, 2009).

\section{Results and discussions}

Results are reported here in two parts: (i) from cross-section surveys, in Table 2 and (ii) based on computation from synthetic panel data, in Table 3. ${ }^{6}$ The former was calculated for a potential growth rate of real per capita income of 1.62 percent per year, which is consistent with the long-term (1960-2015) performance of the Nigerian economy. ${ }^{7}$ In Table 2, we see that as of 1980, all things being equal, it will take the poor approximately 38.6 years to grow out of or escape poverty. By 1996, the total average exit time has risen to 55 years, after which it declines to 46.2 years in 2010 .

Table 2. Welfare measures and average exit time (if $\mathrm{g}=1.62$ percent, growth rate in GDP per capita)

\begin{tabular}{lllllll}
\hline From cross-section & 1980 & 1985 & 1992 & 1996 & 2004 & 2010 \\
\hline Exit time, ave $t$ (years) & 34.5 & 35.6 & 36.9 & 48.54 & 37.9 & 40.8 \\
Theil index among the poor $(\mathrm{Lp})$ & 0.065 & 0.087 & 0.090 & 0.104 & 0.085 & 0.086 \\
Exit time due to inequality $(\mathrm{Lg}=\mathrm{Lp} / \mathrm{g})$ & 4.1 & 5.5 & 5.7 & 6.5 & 5.3 & 5.4 \\
Total ave. exit time, years $($ ave $t+\mathrm{Lg})$ & 38.6 & 41.1 & 42.6 & 55.0 & 43.2 & 46.2
\end{tabular}

Note: Poverty line and PCE are in US\$2005 PPP

Source: Author's calculations based on household surveys of Nigeria

\footnotetext{
${ }^{6}$ Synthetic panel was used because Nigeria has no actual panel dataset. Thus, the sample sizes, across the years, do not differ. The procedure used for constructing synthetic panel can be found in Dang et al. (2014).

7 This value is the average from 1960 to 2012 of per capita income growth of Nigeria from national accounts.
} 
Table 3 shows the exit time as a function of growth in survey mean instead of growth in per capita GDP. We find 44.42 years in 1980 as average exit time, with 1992 reporting the lowest, 35.94 years. The chronically poor spend longer time in poverty (36 to 42 years) than the transient poor, 2 to 15 years. This implies that once poverty is experienced consecutively in two or more periods, it is harder to escape within a short span of time. Inequality among the poor is found to have contributed to the average exit time. In 1996 and 2004, it contributed 11.3 and 4.5 years respectively to the average total exit time.

Table 3. Welfare measures and exit time (using growth rate in survey mean)

\begin{tabular}{|c|c|c|c|}
\hline From synthetic panel & 1980 & 1985 & 1992 \\
\hline Exit time (in years) & 38.7 & 33.34 & 31.1 \\
\hline Sample size & 6,717 & 6,717 & 6,717 \\
\hline Poverty line/year (US\$) & 456.25 & 456.25 & 456.25 \\
\hline PCE mean of the poor (US\$) & 483.8 & 287.6 & 279.4 \\
\hline Thiel index among the poor (Lp) & 0.092 & 0.078 & 0.077 \\
\hline Exit time due to $\mathrm{Lp}(\mathrm{Lg}=\mathrm{Lp} / \mathrm{g})$ & 5.72 & 4.87 & 4.84 \\
\hline Ave total exit time & 44.42 & 38.21 & 35.94 \\
\hline Exit time of the trapped poor & & 38.4 & 36.54 \\
\hline Exit time of the transient poor & & 7.3 & 2.6 \\
\hline \multicolumn{4}{|c|}{ Source: Author's calculations based on household surveys of Nigeria } \\
\hline \multicolumn{4}{|c|}{$\begin{array}{l}\text { The average living standards of the poor during positive growth spells (i.e., between } 1996 \text { and 2004) grew by } \\
4.52 \text { percent (or by } 0.55 \text { per year). If this growth is sustained on an annual basis and is solely relied upon to } \\
\text { lift the poor out of poverty, then, on an average, it will take the poor } 130.28 \text { years to escape of poverty (see } \\
\text { Table 4). It should, however, be noted that of } 21,048 \text { individual poor households in the dataset, } 2,846 \text { (i.e., } \\
13.5 \text { percent) have exit time of less than } 30 \text { years. Also, a noticeable feature is the huge gap between the exit } \\
\text { time based on GDP per capita and based on growth in survey mean or household consumption. This is partly } \\
\text { explained by the fact that rising GDP per capita in the country is seldom mirrored in the average living } \\
\text { standards of the poor. }\end{array}$} \\
\hline \multicolumn{4}{|c|}{$\begin{array}{l}\text { Since the value of } \bar{\gamma} \text { in Table } 4 \text { is found to be negative (i.e., -22.14) it means some individuals in the dataset } \\
\text { are at risk of not escaping poverty in their lifetime. The value of } \sigma \text { in the same table tells us the fraction of } \\
\text { these individuals. As can be seen, relying on growth in GDP per capita, assuming future growth will follow } \\
\text { the pattern of previous growth, more than two-third of the poor are not guaranteed to escape poverty over } \\
\text { the course of their life. Basing this on growth in the income (or consumption of the poor) reveals a darker } \\
\text { side of the poverty situation: about } 91 \text { percent of the poor can expect to spend their lives in poverty. There is } \\
\text { a stark difference between the average daily income (consumption) of those who will escape poverty and of } \\
\text { those who will not, } 209.06 \text { and } \$ 113.60 \text { respectively in January } 2018 \text { prices (Table 4). }\end{array}$} \\
\hline
\end{tabular}




\section{Table 4. Welfare measures, estimated parameters, and the durations of poverty spell}

Description

Parameter

Estimates

Percentage of the poor at risk of spending their life time in poverty, based on annualized growth in:

- GDP per capita

$\sigma \quad 71.73$

- Household per capita consumption expenditure (PCE) of the poor

Average age (in years) of the poor at the time they are expected to escape poverty $[\bar{T}+\bar{A}]$ based on growth in:

- GDP per capita

$\bar{A}^{e} \quad 67.43$

- Household per capita consumption expenditure (PCE) of the poor

178.76

Average life expectancy of the poor after escaping poverty

$\bar{\gamma} \quad-22.14$

Average age of the poor in the 2010 dataset

$\bar{A} \quad 47.48$

Average (over age and gender) of life expectancy of the poor from WHO Life Table

$\bar{L} \quad 22.65$

The sample size of the poor in the 2010 dataset

N 21,048

Poverty line (US\$1.25 PPP 2005) valued in January 2018 prices, Naira/person/day

Z $\quad 317.38$

Average PCE of the poor in 2010 expressed in local currency: Naira/person/day

Average PCE of those likely to escape poverty in their life time

$\mu_{p} \quad 209.60$

Average PCE of those at risk of staying in poverty for life

Annualized growth rate in PCE of the poor between 1996 and 2004 based on (4.58), percent

$\mathrm{g}_{t}^{p} \quad 0.55$

Average annual growth in GDP per capita between 1960 and 2015, percent

g $\quad 1.62$

Average exit time based on annual growth in income of the poor

$\bar{T}_{\mathrm{gp}} \quad 130.28$

Source: Author's calculations based on household surveys of Nigeria 


\section{Policy conclusions}

The poor have not experienced significant growth in their average living standards despite some moderate rise in GDP per capita over the past two decades. Thus, I found growing evidence suggesting a rising deep level of deprivation in Nigeria, rendering more than twothirds of the poor at risk of spending their lifetimes below the poverty line. The clear implication is that growth has not been sufficient nor has it demonstrated the potential to help the poor break free from poverty. This calls for policies that not only bring about a rise in GDP, but also boost the income growth of the poor. Like Brazil, Nigeria can achieve significant poverty reduction without absolute reliance on economic growth by reducing its two-digit inflation rate and substantially expanding its social security and social assistance transfers. Finally, improvements in life expectancy as a health outcome can also improve the chances of the poor of escaping poverty: longer lifespans could shrink the gap between life expectancy and the duration of poverty spell. Unfortunately, Nigeria does not have universal health coverage, which would benefit the poor by making healthcare more affordable.

\section{References}

Andriopoulou, E., \& Tsakloglou, P. (2011). The determinants of poverty transitions in Europe and the role of duration dependence.

Anyanwu, J. C. (2005). Rural poverty in Nigeria: Profile, determinants and exit paths. African Development Review, 17(3), 455-460.

(2010). Poverty in Nigeria: a gendered analysis. African Statistical Journal, 11(11), 3861.

Appleton, S., McKay, A., \& Alayande, B. A. (2008). Poverty in Nigeria. 331-371.

Bane, M. J., \& Ellwood, D. T. (1986). Slipping into and out of Poverty: The Dynamics of Spells. Journal of Human Resources, 21(1), 1-23.

Blundell, R., Duncan, A., \& Meghir, C. (1998). Estimating Labor Supply Responses Using Tax Reforms. Econometrica, 66(4), 827-861.

Canagarajah, S., \& Thomas, S. (2001). Poverty in a Wealthy Economy: the Case of Nigeria. Journal of African Economies, 10(2), 143-173.

Chen, S., \& Ravallion, M. (2008). China is poorer than we thought, but no less successful in the fight against poverty (Vol. 4621). World Bank Publications.

Clark, D., \& Hulme, D. (2005). Towards a Unified Framework for Understanding the Depth, Breadth and Duration of Poverty. Economics Series Working Papers(GPRGWPS-020).

Dang, H. A., Lanjouw, P., Luoto, J., \& McKenzie, D. (2014). Using repeated cross- sections to explore movements into and out of poverty. Journal of Development Economics, 107, 112-128.

Deaton, A. (1985), Panel Data from Time Series of Cross Sections, Journal of Econometrics, 30, 109-126.

Deaton, A. (1997). The analysis of household surveys: a microeconometric approach to development policy. World Bank Publications. 
Duncan, G. J., Coe, R., Corcoran, M., Hill, M. S., Hoffman, S., \& Morgan, J. N.

(1984). Years of poverty, years of plenty: The changing economic fortunes of American workers and families.

FOS, (1999). Poverty Profile for Nigeria: a Statistical Analysis of 1996/97 National Consumer Survey (with reference to1980, 1985,92).

Haughton, J., \& Khandker, S. R. (2009). Handbook on Poverty and Inequality. World Bank Publications.

Jalan, J., \& Ravallion, M. (2002). Geographic poverty traps? A micro model of consumption growth in rural China. Journal of applied econometrics, 17(4), 329-346.

Kuznets, S. (1955). Economic growth and income inequality. The American economic review, 45(1), 1-28.

Lundberg, M., \& Squire, L. (2003). The simultaneous evolution of growth and inequality. The Economic Journal, 113(487), 326-344.

Morduch, J. (1998). Poverty, economic growth, and average exit time. Economics Letters, 59(3), 385-390.

NBS, Annual Socio-Economic Report abstract contains in Nigerian: Unemployment Report 2011. Retrieved from Abuja, Nigeria.

Ravallion, M., \& Chen, S. (2003). Measuring pro-poor growth. Economics Letters, 78(1), 93 99.

Sangraula, P \& Ravallion, M, Chen, S., \& (2009). Dollar a day revisited. The World Bank Economic Review, 23(2), 163-184.

Stevens, A. H. (1994). The dynamics of poverty spells: Updating Bane and Ellwood. The American Economic Review, 84(2), 34-37.

Sudharshan, Ngwafon and Saji (2002). Poverty in a Wealthy Economy: the case of Nigeria (Vol. 2). International Monetary Fund. 